contacts, however, yielded 12 patients with the disease, of whom eight were children, which underlines the efficiency of the service if properly applied.

The public reaction to the articles in local papers was interesting, and evidently there are still many misconceptions about tuberculosis. Most of the people who submitted themselves for $x$ ray examination were totally ignorant of the implications of the disease and reacted in a way more reminiscent of the plague or smallpox. This shows again how powerful an influence the media may be in medical matters. The unjustified loss of trade to the public house must also be a matter of some concern and reflects to some extent the public attitude to the disease.

In conclusion, this epidemic serves to emphasise two long established but probably forgotten truths about tuberculosis. Firstly, tuberculosis still exists in this country and is not merely a disease of immigrants, social outcasts, and alcoholics; in non-vaccinated people it remains a highly contagious disease of young adulthood. The BCG vaccination, however, is safe, free from systemic side effects, and of proved efficacy when given at the age of maximum susceptibility to the disease. Every effort should be made to pursue the schools vaccination programme, particularly in children who initially default. Secondly, the public should be made aware that tuberculosis in all forms can be cured completely with drugs at little personal inconvenience.

We thank the Bradford chest physicians for access to their patients.

\section{References}

1 Joint Tuberculosis Committee of the British Thoracic Association. Notification of tuberculosis: a code of practice for England and Wales. Br Med F 1982;284:1454-6.

2 Wardman AG, Williams SE, Curzon PGD, Page RL, Cooke NJ. Tuberculosis: who should prescribe? $\mathrm{Br}$ Med $\mathcal{F} 1982 ; 284: 569-73$.

${ }^{3}$ Research Committee of the British Thoracic Association. Report. Effectiveness of BCG vaccination in Great Britain in 1978. $\mathrm{Br} \mathcal{F}$ Dis Chest $1980 ; 74: 215-27$.

${ }^{4}$ Smith WHR, Davies D, Mason KD, Onions JP. Intraoral and pulmonary tuberculosis following dental treatment. Lancet 1982;i:842-4.

${ }^{5}$ Spencer-Jones J. A tuberculosis outbreak in Deal, Kent. Lancet 1982; i : 1060-1.

${ }^{6}$ Communicable Disease Surveillance Centre. Communicable disease report 1979 , No $9 ; 1979$, No $22 ; 1980$, No $23 ; 1980$, No $50 ; 1981$, No $36 ; 1982$, No 11 .

(Accepted 9 March 1983)

\title{
Clinical range of neonatal rotavirus gastroenteritis
}

\author{
J DEARLOVE, P LATHAM, B DEARLOVE, K PEARL, A THOMSON, I G LEWIS
}

\begin{abstract}
A baby admitted to a special care baby unit with profuse watery diarrhoea was found to have a rotavirus infection. A total of 196 babies were admitted to the unit over the next year. Routine stool samples were taken weekly from all babies and additional samples were taken from all babies who developed clinical signs suggesting sepsis. A total of 76 babies excreted rotavirus; 32 of these developed a diarrhoeal illness, 12 of whom were severely ill with bloody diarrhoea and abdominal distension; and two had perforations. The smaller, sicker babies who stayed in hospital longer were more likely to acquire infection; colostrum did not confer protection against rotavirus or symptomatic infection. The outbreak of rotavirus declined independently of the measures taken to eradicate it.
\end{abstract}

Our findings suggest that neonatal rotavirus infection may occasionally cause severe gastrointestinal problems.

Ormskirk and District General Hospital, Ormskirk L39 2AZ

J DEARLOVE, FRCP(C), MRCP, consultant paediatrician

B DEARLOVE, MSC, research worker

Department of Paediatrics, Charing Cross Hospital, London W6 8RF P LATHAM, MRCP, senior registrar

South Hammersmith District Health Authority, London W6

K PEARL, MRCP, senior clinical medical officer, South Hammersmith District

Department of Paediatrics, Hammersmith Hospital, London W12 A THOMSON, MRCP, research registrar

Department of Paediatrics, Queen Victoria Hospital, Adelaide, S Australia

I G LEWIS, MB, MRCP, lecturer in neonatology

Correspondence to: Dr J Dearlove.

\section{Introduction}

In December 1980 an infant was admitted to the special care baby unit at Charing Cross Hospital. He developed a profuse watery diarrhoea. Rotavirus was isolated from his stools and also from his mother's faeces. Over the next year we treated a large number of infected babies with a very high morbidity. Although neonatal rotavirus infections are generally regarded as relatively benign, ${ }^{1}$ our experience was very different. ${ }^{2}$

\section{Materials and methods}

All babies admitted to the special care baby unit in the year after the index case-that is, from 18 December 1980 to 18 December 1981were studied. Cases arising after 18 December 1981 were excluded from the study. All the babies studied were seen by at least two of the authors. Later in the study period, we attempted a similar surveillance of asymptomatic babies in the postnatal wards, but those results are not included here.

An initial stool sample was taken from all babies; thereafter stool samples were taken weekly and cultured for bacterial pathogens. Stools were also examined for the presence of rotavirus. In addition, any baby who appeared ill and was being investigated for a septic condition had a stool sample examined for the presence of rotavirus. Initially, the stool specimens were examined by electron microscopy. After three months, this technique was replaced by semiquantitative enzyme linked immunoassay (Rotazyme), which is of comparable sensitivity ${ }^{3}$ as we found when using both techniques at the beginning of our study. The Rotazyme test may give negative results or be graded optically as positive from one (weakly positive) to six (very strongly positive). We regarded a result of grade two, as indicative of rotavirus infection. The date that the first stool with positive results was taken from the patient was assumed to be the date that the baby acquired rotavirus. The date in the baby's notes indicating a clear change in clinical state as defined by our criteria was taken to be the date that the baby became ill.

The babies who excreted rotavirus appeared to have a wide range of gastrointestinal symptoms varying in severity from those resembling necretising enterocolitis to mild diarrhoea. The babies were classified 
as having severe or mild diarrhoea. Our definition of mild diarrhoea was: a stool frequency that was at least twice the frequency of the previous day and the nurses had recorded this as diarrhoea and the baby was investigated for this. Although this definition necessitated a consensus discussion by all the medical staff, it avoided including babies who had suddenly increased their stool frequency from say one to two stools a day. These babies with diarrhoea were then classified according to treatment. Some babies with mild diarrhoea by the above criteria none the less appeared very ill. These babies were classified as having severe diarrhoea if, in addition to diarrhoea, they had (a) signs suggestive of infection - that is, lethargy, hypotonia, or apnoeic spells; (b) bloody diarrhoea visible to the naked eye; (c) abdominal distension; (d) gaseous distension or frothy appearance of the bowel lumen, or
Table I shows the number of babies admitted each month and the numbers with rotavirus (with and without symptoms). The number of babies who excreted rotavirus broadly follows the monthly admission rate. Table II shows the characteristics of the 196 babies. Those who did not acquire infection were older, heavier, and stayed in the special care unit for a shorter period than those who caught rotavirus. In addition, more formula fed babies excreted rotavirus. Although more babies who developed rotavirus in their stools were receiving ventilation and had arterial lines and nasojejunal tubes there was no significant difference in these three factors between the babies who had symptomatic rotavirus infections and those who were asymptomatic.

What was striking was that the onset of gastrointestinal symptoms coincided with the detection of rotavirus in the babies' stools to

TABLE I-Distribution of cases of rotavirus infection over one year in relation to number of cases admitted to special care unit

\begin{tabular}{lcrrrrrrrrrrrr}
\hline & Dec & Jan & Feb & Mar & Apr & May & Jun & Jul & Aug & Sep & Oct & Nov & Dec \\
\hline No of admissions $(n=196)$ & 6 & 9 & 11 & 17 & 9 & 20 & 31 & 20 & 22 & 16 & 14 & 12 & 9 \\
No with rotavirus: & 2 & 1 & 0 & 8 & 1 & 4 & 6 & 3 & 1 & 2 & 1 & 2 & 1 \\
Symptomatic $(\mathrm{n}=32)$ & 1 & 1 & 2 & 3 & 4 & 5 & 7 & 6 & 6 & 3 & 2 & 3 & 1 \\
Asymptomatic $(\mathrm{n}=44)$ & 3 & 2 & 2 & 11 & 5 & 9 & 13 & 9 & 7 & 5 & 3 & 5 & 2
\end{tabular}

TABLE II-Characteristics of 196 babies in special care baby unit. Figures are mean $(S D)$

\begin{tabular}{|c|c|c|c|c|}
\hline & \multicolumn{3}{|c|}{ With rotavirus } & \multirow{2}{*}{$\begin{array}{l}\text { Without rotavirus } \\
\qquad(\mathrm{n}=120)\end{array}$} \\
\hline & $\underset{(n=32)}{\text { Symptomatic }}$ & $\begin{array}{c}\text { Asymptomatic } \\
(n=44)\end{array}$ & $\begin{array}{c}\text { Total } \\
(\mathrm{n}=76)\end{array}$ & \\
\hline $\begin{array}{l}\text { Gestation (weeks) } \\
\text { Weight (kg) } \\
\text { No with weight appropriate for dates } \\
\text { No of days in unit (range) }\end{array}$ & $\begin{array}{c}33.5(4 \cdot 4) \\
1.99(0.8) \\
28 \\
34 \cdot 4\end{array}$ & $\begin{array}{c}33.5(4 \cdot 0) \\
1.95(0.8) \\
33 \\
33.8\end{array}$ & $\begin{array}{c}33 \cdot 5(4 \cdot 2)^{*} \\
1.97(0 \cdot 8)^{*} \\
66 \\
34 \cdot 1(2-104)\end{array}$ & $\begin{array}{l}37 \cdot 5(3 \cdot 0) \\
2 \cdot 82(0 \cdot 7) \\
101 \\
5 \cdot 8(2-71)\end{array}$ \\
\hline $\begin{array}{l}\text { No receiving treatment: } \\
\text { Ventilation } \\
\text { Nasojejunal tube } \\
\text { Intra-arterial line } \\
\text { Antibiotics on admission }\end{array}$ & $\begin{array}{r}7 \\
15 \\
15 \\
18\end{array}$ & $\begin{array}{l}10 \\
13 \\
12 \\
13\end{array}$ & $\begin{array}{l}17^{*} \\
28^{*} \\
27^{*} \\
31\end{array}$ & $\begin{array}{r}5 \\
4 \\
10 \\
27\end{array}$ \\
\hline $\begin{array}{l}\text { Details of feeding: } \\
\text { No given maternal colostrum as first feed } \\
\text { No given breast milk only } \\
\text { No formula fed } \\
\text { No receiving breast and formula }\end{array}$ & $\begin{array}{r}7 \\
1 \\
25 \\
6\end{array}$ & $\begin{array}{r}10 \\
5 \\
25 \\
14\end{array}$ & $\begin{array}{l}17 \\
6 \\
50^{*} \\
20\end{array}$ & $\begin{array}{l}18 \\
16 \\
41 \\
63\end{array}$ \\
\hline
\end{tabular}

* Babies with rotavirus infection $v$ those without $\mathrm{p}<0.001$.

both, on abdominal $x$ ray; (e) pneumatosis intestinalis visible on $x$ ray; or $(f)$ perforation.

All comparisons were made using a $\chi^{2}$ test for the non-parametric data. Continuous variables were expressed as the mean ( $\pm 1 S D)$ and comparisons were made using Student's $t$ test.

\section{Results}

A total of 1925 babies were delivered in the Charing Cross Hospital from December 1980 to December 1981. The total number of cases of rotavirus infection was 113 , of which 76 were in the special care baby unit. The remaining 37 babies were from the postnatal wards and had had gastrointestinal problems resulting in rotavirus being detected in their stools. Of these 37, three needed intravenous rehydration and were transferred to the special care unit. All three had bloody diarrhoea and only one had abnormal appearance on $x$ ray film. The first case detected on the postnatal wards occurred three weeks after the onset of the outbreak in the special care unit. As routine surveillance of asymptomatic babies in the postnatal wards did not start until later in the year, we have not attempted to compare the findings in the postnatal wards with those in the special care baby unit. As, however, we had started a weekly screening service for stool pathogens, including rotavirus, in our special care baby unit, we thought we could compare the characteristics of the babies on the special care unit who became infected with those who did not over the period 18 December 1980 to 18 December 1981.

A total of 196 babies were admitted to the special care unit during the study period. Of these, 76 excreted rotavirus in their stools as measured by an enzyme linked immunoassay: the remaining 120 never excreted rotavirus. within a day (see tables III and IV). The time taken for the stools to clear of rotavirus had little relation to the duration of symptoms. Nevertheless, the time taken differed little between the babies who had acquired a symptomatic rotavirus infection (10.8 days) and those who had acquired an asymptomatic infection $(11 \cdot 1$ (9.8 days)), despite the different way in which the samples were obtained.

Stools that were negative for rotavirus either on electron microscopy or using the Rotazyme assay were considered to be clear of rotavirus. Using these criteria, 10 babies acquired rotavirus, were then found to be clear of infection, and then appeared to have reacquired it about 12 days later. These babies were usually asymptomatic (only one had

TABLE III-Relation between symptoms and rotavirus excretion in babies with severe and mild diarrhoea. Figures are mean $(S D)$

\begin{tabular}{|c|c|c|}
\hline & $\begin{array}{l}\text { With rotavirus } \\
\qquad(\mathrm{n}=76)\end{array}$ & $\begin{array}{l}\text { Without rotavirus } \\
\qquad(\mathrm{n}=120)\end{array}$ \\
\hline \multicolumn{3}{|l|}{ Babies with severe diarrhoea: } \\
\hline $\begin{array}{l}\text { No } \\
\text { Age at onset of symptoms (days) }\end{array}$ & $\begin{array}{c}12 * \\
10 \cdot 9(6 \cdot 5)\end{array}$ & $17 \cdot 75^{4}(12 \cdot 6)$ \\
\hline Age at acquisition of infection (days) & $10 \cdot 8(7 \cdot 0)$ & \\
\hline $\begin{array}{l}\text { Duration of symptoms (days) } \\
\text { Duration of injection (days) (range) }\end{array}$ & $\begin{array}{c}8 \cdot 3(6 \cdot 4) \\
21 \cdot 8(2-90)\end{array}$ & $5 \cdot 5(1 \cdot 9)$ \\
\hline \multicolumn{3}{|l|}{ Babies with mild diarrhoea: } \\
\hline $\begin{array}{l}\text { No } \\
\text { Age at onset of symptoms (days) }\end{array}$ & $\begin{array}{c}20 \\
13 \cdot 1(9 \cdot 9)\end{array}$ & $7.5(3.5)$ \\
\hline Age at acquisition of infection (days) & $13 \cdot 2(9 \cdot 8)$ & \\
\hline $\begin{array}{l}\text { Duration of symptoms (days) } \\
\text { Duration of infection (days) }\end{array}$ & $\begin{array}{c}4 \cdot 0(3 \cdot 3) \\
15 \cdot 4(13 \cdot 8)\end{array}$ & $4 \cdot 5(2 \cdot 1)$ \\
\hline
\end{tabular}
* Three babies with severe diarrhoea who were transferred from postnatal wards to
the unit have been excluded. 
TABLE IV-Distribution of physical signs in 196 babies admitted to the special care unit. Figures are numbers of patients

\begin{tabular}{lcc}
\hline & $\begin{array}{c}\text { With rotavirus } \\
(\mathrm{n}=76)\end{array}$ & $\begin{array}{c}\text { Without rotavirus } \\
(\mathrm{n}=120)\end{array}$ \\
\hline Babies with severe diarrhoea* & 12 & 4 \\
Total & 2 & 0 \\
Perforation & 3 & 1 \\
Pneumatosis & 10 & 4 \\
Abnormal bowel pattern & 11 & 4 \\
Bloody diarrhoea & 12 & 4 \\
Abdominal distension & 12 & 2 \\
Signs suggestive of sepsis & 20 & 1 \\
Bobies with mild diarrhoea & & 4 \\
Needing intravenous fluids & 5 & 0 \\
Needing oral rehydration & 11 & \\
Needing no treatment & 4 & \\
\hline
\end{tabular}

* Babies with rotavirus $v$ those without; $\mathrm{p}-0.01$.

* Babies with rotavirus $v$ those without; $p<0.01$
+ Babies with rotavirus $v$ those without; $p<0.001$

diarrhoea, compared with 32 from the original sample of 76). The babies who were reinfected were also more likely to have stayed on the unit longer, about 65 days, compared with only 34 days for babies who had only one infection.

\section{Discussion}

There are two aspects to our study. It is, firstly, a description of a rotavirus epidemic, pointing out that smaller, sicker babies get infected and that the longer the baby stays in an infected unit the more likely it is to get a second infection. The second, and more difficult, aspect to the study is linking the clinical signs to the acquisition of rotavirus. In December 1980 we noticed two clinical problems affecting our babies; a diarrhoeal illness and slow weight gain. It became clear that slow weight gain could not be attributed to rotavirus. Rotavirus is, however, a common cause of acute infantile diarrhoea and it has been described in neonates. ${ }^{4}$ About half of the babies who had rotavirus in their stools also had symptoms and onset of symptoms often coincided with acquisition of infection. Obviously we cannot say that rotavirus was the prime cause of illness in the sick babies, despite the rather compelling circumstantial evidence.

Our study could be criticised on several points. For example, we did not examine every sample by electron microscopy as well as Rotazyme assay and may, therefore, have missed other viruses. ${ }^{5}$ When we used the combined technique at the outset of this study, however, we could not identify other viruses in the stools of these babies. We learnt several practical lessons. Fumigation of the unit performed in August and September appeared to have little effect on rates of infection, as did strict hand washing and wearing disposable aprons. Giving the first feed as fresh maternal colostrum offered no protection against gastroenteritis or rotavirus. We thought that the weighing scales, the sterilising solution, or the ventilators could have been contaminated with rotavirus but we could not detect antigens or isolate rotavirus from these sources. We did notice, however, that the symptomatic cases clustered around the times when we were busiest with new admissions. Curiously, the rotavirus epidemic waned over the first half of 1982, despite admission rates similar to those of 1981 : this bore no obvious relation to our measures to control infection.

Finally, when we originally described our experience, ${ }^{2}$ we thought that some of our babies who had a rotavirus infection also appeared to have necrotising enterocolitis. This diagnosis was based on the British Paediatric Association's surveillance criteria, which recognises two grades of severity of necrotising enterocolitis. Grade I needs two of our five criteria (excluding perforation) for severe diarrhoea. Although our cases of severe diarrhoea might fulfil these criteria, all but the three with pneumatosis could also be diagnosed as gastroenteritis. Because of this lack of specificity, we decided that only the cases with all five clinical signs and with radiological evidence of pneumatosis intestinalis had necrotising enterocolitis. This would mean that three out of 76 babies who excreted rotavirus had necrotising enterocolitis around the same time, compared with one out of 120 babies with no rotavirus. Although this is a significant difference $(p<0.02)$, the numbers are very small indeed. This finding does, however, underline the suggestion that neonatal rotavirus infections may occasionally cause severe gastrointestinal problems.

We thank Dr I Chrystie for valuable help; Dr K McCrae for statistical advice; Dr Noah for his useful review of the BPA/PHLS Necrotising Enterocolitis Survey; the nurses and doctors on the special care baby unit, West London Hospital, for their time and skill; the departments of medical illustration, Charing Cross Hospital and the Preston Royal Infirmary; and Mrs Barbara Longley and Ms Andrea Cronshaw, who prepared this manuscript.

\section{References}

1 Chrystie K, Totterdell BM, Banatvala JE. Asymptomatic endemic rotavirus infections in the newborn. Lancet 1978;ii:1176-8

2 Thomson AH, Dearlove J, Lewis I, Latham P, Birkin N, Keogh A. Outbreak of rotavirus gastroenteritis among premature infants. Br Med $\mathcal{f}$ $1981 ; 283$ : 1405 .

${ }^{3}$ Yolken R, Kim H, Clem T, et al. Enzyme-linked immunosorbent assay to detect human reovirus-like agent of infantile gastroenteritis. Lancet 1977 ;ii :263-6.

${ }^{4}$ Murphy A, Albrey M, Crewe E. Rotavirus infections in neonates. Lancet 1977; ii:1149-50.

5 Van Renterghen L, Borre PM, Tilleman J. Rotavirus and other viruses in the stool of premature babies. $f$ Med Virol 1980;5:137-42.

(Accepted 17 February 1983)
REPELLING MEDICINES-Repelling medicines are of contrary operation to these three last mentioned, viz attenuating, drawing, and discussive medicines: It is true, there is but little difference between these three, some hold none at all: and if you will be so nice, you may oppose them thus. And so medicines making thick, correspond to attenuating medicines, or such as make thin, repelling medicines are opposed to such as draw, and such as retain the humours and make them tough, are opposite to such as discuss, some hold this niceness needless. 2. The sentence of authors about repulsive medicines is various. For seeing an influxion may be caused many ways, a repulsive hath got as many definitions. For such things as cool, bind, stop, and make thick, stay influxions, and therefore repulsives are by authors opposed, not only to attractives, but also to attenuating, and discussing medicines. But properly such things are called repulsives, which do not only stay influxions (for so do such medicines which stop and make thick) but such as drive the humours flowing to, or inherit in the place, to some other place. The truth is, binding is inherent to repulsives, so is not coldness nor making thick: Yet such as are binding, cold and thin in operation, are most effectual. Your taste will find repulsives to be, tart, or sharp, or austere, with a certain binding which contracts the tongue. Their use is manifold, as in hot tumours, head-aches, or the like. By these in fevers are the vapours driven from the head, Vinegar or Roses is notable. They are most commodious in the beginning and encrease of a disease, for then influxions most prevail. But seeing that in the cure of tumours there are two scopes, 1 . That that which flows to it may be repelled. 2. That that which is already in it may be discussed; repulsives are most commodiously used in the beginning, discussives in the latter end. In the middle you may mix them, with this proviso, that repulsives exceed in the beginning, discussives in the latter end. Caution 1 . If the matter offending be of a venomous quality, either abstain from repulsives altogether, or use purging first, lest the matter fly to the bowels and prove dangerous, especially if the bowels be weak. 2. Also forbear repulsives, if the pain be great. 3. Lastly, Have a care lest by repulsives you contract the pores so much, that the matter cannot be removed by discussives. (Nicholas Culpeper (161654) The Complete Herbal, 1850.) 